\title{
Article
}

\section{Analysis of external workload in soccer training and competition: generic versus individually determined speed thresholds}

Kavanagh, R., and Carling, Christopher

Available at http://clok.uclan.ac.uk/25398/

Kavanagh, R., and Carling, Christopher ORCID: 0000-0002-7456-3493 (2019) Analysis of external workload in soccer training and competition: generic versus individually determined speed thresholds. Science and Medicine in Football, 3 (1). pp. 83-84. ISSN 2473-3938

It is advisable to refer to the publisher's version if you intend to cite from the work. http://dx.doi.org/10.1080/24733938.2018.1562279

For more information about UCLan's research in this area go to http://www.uclan.ac.uk/researchgroups/ and search for <name of research Group>.

For information about Research generally at UCLan please go to http://www.uclan.ac.uk/research/

All outputs in CLoK are protected by Intellectual Property Rights law, including Copyright law. Copyright, IPR and Moral Rights for the works on this site are retained by the individual authors and/or other copyright owners. Terms and conditions for use of this material are defined in the policies page. 
Title: Analysis of external workload in soccer training and competition: generic versus individually determined speed thresholds.

Authors: Ronan Kavanagh ${ }^{1}$, Christopher Carling ${ }^{2}$

Institutions:

${ }^{1}$ Department of Sports Science, Burnley Football Club, Burnley, UK.

${ }^{2}$ Institute of Coaching and Performance, University of Central Lancashire, Preston, UK.

Correspondence: Christopher Carling, Institute of Coaching and Performance, University of Central Lancashire, Preston, United Kingdom.

Email: ccarling@uclan.ac.uk

Phone: +44 (0)1772 891998

ORCID iD: 0000-0002-7456-3493

Key words: performance, football, monitoring, GPS, tracking

Word Count: 1109

Disclosure of interest: The authors have no potential conflict of interest and no funding was obtained for the preparation of this article. 


\section{Title: Analysis of external workload in soccer training and competition: generic versus individually determined speed thresholds.}

Dear Editor, we read with interest a recent article published in Science and Medicine in Football employing datamining techniques in an attempt to determine new time-motion analysis speed thresholds for elite women football players (Park et al. 2018). This article fits in with the continual need to hone monitoring techniques and aid understanding of external loads in contemporary training and match-play. Information can aid practitioners in manipulating physical output and monitoring responses to the stimulus to help players respond to playing demands whilst attempting to reduce the risk of incurring injury.

Historically, external workload has been determined using high-speed and sprinting outputs generally represented by distances covered above generic or arbitrary playerindependent speed thresholds (or zones) of $5.5 \mathrm{~m} / \mathrm{s}$ and $7 \mathrm{~m} / \mathrm{s}$ respectively. These thresholds have frequently been used in professional football especially since the introduction of semiautomated camera systems, and were universally adopted by the major contemporary commercial GPS and Optical tracking companies. As a result, they have found their way into the scientific literature and football industry despite a lack of scientific investigations providing an empirical technical, tactical and physiological grounding. As performance indicators, generic thresholds allow practitioners to compare running outputs at an absolute level across teams, individual players, playing positions and standards using the same criteria. However, when a generic speed threshold of $5.5 \mathrm{~m} / \mathrm{s}$ was used on a squad average basis to quantify the high-intensity running distance covered by elite players in competition, outputs were substantially underestimated in comparison to data adjusted according to individual speed thresholds derived from physiological testing (Abt \& Lovell, 2013). Similarly, while a threshold of $7 \mathrm{~m} / \mathrm{s}$ is widely used to classify sprinting distance in elite professional football, peak speeds ranging between 8.2 and $9.7 \mathrm{~m} / \mathrm{s}$ have been reported across players (Rampinini et al. 2007). As such, sprinting distance can be substantially overestimated in training and matchplay in some players. Recently Colby et al. 2018 suggested that in order to reduce injury risk, athletes should be exposed to near maximal velocities on a regular basis. As a result, it would seem more logical to monitor running activity above $95 \%$ of each individual's peak speed as opposed to a generic threshold.

In our opinion, the article by Park and colleagues has employed a fresh approach to determining time-motion analysis speed thresholds via datamining techniques. These techniques can be used to group athlete velocity data and determine patterns within athlete movements, without the requirement of a human input threshold based on a physiologically defined or arbitrary value (Sweeting et al., 2017). Yet we ask whether high speed running and sprinting data derived using these techniques are sufficient to provide an accurate representation of the true loads elicited upon players especially if we are to account for interindividual differences in physical characteristics? It is recognised that there are substantial discrepancies in locomotor outputs if absolute data are not adjusted using individualised speed thresholds (Schimpchen et al., 2016) especially when these are derived from values for peak sprinting speed and/or aerobic fitness (Abt \& Lovell, 2011; Lovell \& Abt, 2013; Hunter et al. 2015; Abbott et al. 2018a) and more recently, maximum accelerative capacity (Abbott et al. $2018 \mathrm{~b}$ ). In the absence of adjustments, identical external training loads could elicit considerably contrasting internal loads in players with different individual characteristics. Practitioners unable to administer a player specific approach to performance monitoring and training prescription might find the training stimulus appropriate for one athlete, but inappropriate (too high or too low) for another. Subsequently players may be underprepared for the physical demands of the game or exposed to 'spikes' in external load potentially 
increasing the risk of them being pushed beyond their physical limits and eventually breaking down. Indeed, there are difficulties in defining which acute:chronic workload ratio values are critical when monitoring players with varying or unknown fitness levels (Buchheit, 2016).

While we acknowledge that a simple measure of aerobic fitness does not enable prediction of injury or performance, an easily-administered field test to determine maximal aerobic speed as a speed threshold (despite its acknowledged limitations) could enable prescription of external loads tailored to each individual or if practically difficult, to small groups including players with similar values. A more tailored approach to training prescription could engender improvements in aerobic fitness thereby increasing athletes' resilience to higher workloads through protectively moderating the workload effect by 'dimming' or reducing the risk of rapid workload increases (Windt et al., 2017). Similarly, if a player performs poorly in a pre-season fitness test or is returning to play following injury, practitioners could theoretically adjust his/her 'permitted' workload threshold according to current fitness status, whilst providing personalised attention to address the deficiency (Windt et al., 2017). In line with these points, external workloads are sometimes used as indicators of competitive performance and therefore running outputs of certain players may again be under-or over-estimated. Some practitioners also attempt to make inferences from external match load data to post-match stress and readiness to play status and adjust training loads accordingly (Carling et al., 2018). Again, arbitrary speed thresholds might not truly depict players efforts possibly leading to mistakes in interpreting fatigue and readiness for participation in training or selection for competition. Accounting for individual fitness measures could also have pertinence when monitoring youth players moving across age categories and when changes in maturation status occur. While current practice commonly assesses academy players using the same generic speed thresholds as senior squad peers, it is in our opinion that a more individualised approach across the board to monitoring development and tailoring training prescription is merited with the aim of aiding transitioning of players to first team training and match environments.

Finally, beyond the debate on arbitrary versus individualised thresholds, we agree with Drust (2018) who suggests that greater impetus should now be placed on examining the methodological and practical implications of using individualised speed thresholds rather than demonstrating that another different scaling factor simply leads to another set of outcomes in the classification of activities. While the individualisation of speed thresholds in relation to dose-response in football training has resulted in inconclusive findings (Fitzpatrick et al. 2018; Scott \& Lovell, 2018) thereby warranting additional investigation, particularly at elite male senior standards, we feel that there is a real need to move towards the application of relative thresholds to workload data and particularly towards intervention-based research using individual physical capacities such as peak speed (match and test derived) and aerobic fitness, both singly and in combination, to set thresholds and subsequently monitor and dose external workload. Despite the recognised practical difficulties encountered in conducting applied research in elite soccer club settings, future investigations should aim to quantify the impact of such interventions upon fitness characteristics, injury occurrence, and competitive match performance outcomes.

\section{References}

Abbott W, Brickley G, Smeeton N. (2018a). An individual approach to monitoring locomotive training load in English Premier League academy soccer players. Int J Sports Sci Coach. 13(3):421-428.

Abbott W, Brickley G, Smeeton NJ, Mills S. (2018b). Individualizing Acceleration in English Premier League Academy Soccer Players. J Strength Cond Res. In press. 
Buchheit M. (2016). Applying the acute:chronic workload ratio in elite football: worth the effort? Bri J Sports Med. 51(18):1325-1327.

Carling C, Lacome M, McCall A, Dupont G, Le Gall F, Simpson B, Buchheit M. (2018). Monitoring of Post-match Fatigue in Professional Soccer: Welcome to the Real World. Sports Med. In Press.

Colby MJ, Dawson B, Peeling P, Heasman J, Rogalski B, Drew, MK, Stares J. (2018). Repeated exposure to established high risk workload scenarios improves non-contact injury prediction in elite Australian footballers. Int J Sports Phys Perform. In press.

Drust B. 2018. An individual approach to monitoring locomotive training load in English Premier League academy soccer players. Int J Sports Sci Coach. 13(3):429-430.

Fitzpatrick JF, Hicks KM, Hayes PR. (2018). Dose-Response Relationship between Training Load and Changes in Aerobic Fitness in Professional Youth Soccer Players. Int J Sports Physiol Perform. In press.

Gabbett TJ. 2016. The training-injury prevention paradox: should athletes be training smarter and harder? Br J Sports Med. 50(5):273-280.

Hunter F, Bray J, Towlson C, Smith M, Barrett S, Madden J, Abt G, Lovell R. Individualisation of time-motion analysis: a method comparison and case report series. Int J Sports Med. 2015 36(1):41-8.

Murray NB, Gabbett TJ, Townshend AD. (2017). The Use of Relative Speed Zones in Australian Football: Are We Really Measuring What We Think We Are? Int J Sports Physiol \& Perform. 13(4):442-451.

Lovell R, Abt G. (2013). Individualization of Time-Motion Analysis: A Case-Cohort Example. Int J Sports Physiol \& Perform. 8(4):456-458.

Park, LAF, Scott D \& Lovell R. (2018): Velocity zone classification in elite women's football: where do we draw the lines? Sci Med Football. In press.

Rampinini E, Coutts AJ, Castagna C, Sassi R, Impellizzeri FM. 2007. Variation in top level soccer match performance. Int J Sports Med. 28(12), 1018-1024.

Scott, D. Lovell, R. 2018. Individualisation of speed thresholds does not enhance the doseresponse determination in football training. J Sports Sci. 36(13):1523-1532.

Schimpchen J, Skorski S, Nopp S, Meyer T. Are "classical" tests of repeated-sprint ability in football externally valid? A new approach to determine in-game sprinting behaviour in elite football players. J Sports Sci. 2016;34(6):519-26.

Sweeting AJ, Cormack SJ, Morgan S, Aughey RJ. When Is a Sprint a Sprint? A Review of the Analysis of Team-Sport Athlete Activity Profile. Front Physiol. 2017. 20(8):432.

Windt J, Zumbo BD, Sporer B, MacDonald K, Gabbett TJ. 2017. Why do workload spikes cause injuries, and which athletes are at higher risk? Mediators and moderators in workload injury investigations. Br J Sports Med. 51(13):993. 